\title{
Foucault and Social Measure
}

\section{Mary Beth Mader}

Michel Foucault's arguments for the importance of the modern social technology of the norm have received much scholarly attention. But in most cases a philosophical explication of the supposed novelty of the norm on the level of its very basic conceptual operation is lacking. This paper offers analysis of and speculation on the conceptual operation of statistical measure as a part of the political technology of biopower. It further aims to examine the ontological dimension of the social technology of the norm and of social statistical measure. Its starting point, then, is Foucault's underexploited insight into the specificity of normalization as a central and novel element of the mutation in power that he calls "modern biopower."

The paper is not a work in statistical theory or in the history of statistics; it seeks rather to articulate the conceptual level of the operation of normalization through a focus on the operation of statistical measurement as found in the normal curve and other like instruments of social statistics. It proposes that in order to sense fully the novelty and centrality of normalizing techniques, attention must be paid to the specific nature of statistical measurement. It is by such attention that we can seize the specificity and novelty of the continuous nature of the new power over life that Foucault analyzes. In particular, this attention helps to distinguish the norm from a law and from a rule, custom, or tradition.

The paper attempts several things: part one argues for the importance to Foucault's account of biopower of a statistical conception of the norm and of its role in the constitution of the continuities that characterize that form of power. A full conceptual analysis of the 


\section{MARY BETH MADER}

complex technology that is the normal curve is precluded here for reasons of space. But part two seeks to apply the point about the importance of the norm in the creation of continuities to a simpler statistical notion implicitly included in the norm, namely, the ratio. It then extends Foucault's argument to speculate that numerical continuities expressed in the ratios of social measure can obscure both ontological discontinuities and social relations.

Many of the criticisms of the statistical constitution of social continuities that are advanced in part two are not unprecedented in themselves. Indeed, some commentators have critiqued the roles of statistics in state administration, law and the social sciences as illegitimately homogenizing operations from the very time of their historical emergence. ${ }^{1}$ The purpose of introducing these criticisms into discussion of Foucault's work is to shed light on Foucault's own thought, and to extract and amplify his epistemic claims about the operation of statistical tools in the crafting of continuities.

\section{Measures of life: biopower and statistics in the work of Foucault}

A normalizing society is the historical outcome of a technology of power centered on life ${ }^{2}$

Foucault extends Georges Canguilhem's largely biomedical, partially statistical, and marginally social accounts of normativity and normalization into a technopolitics that lends great significance to the role of the statistical norm. ${ }^{3}$ He argues that the emergence of normalizing practices characterizes the age of modern biopower, distinguishing this kind of power from the sovereign power of the previous age. ${ }^{4}$ On this well-known account, two forms of biopower develop since the seventeenth century. These two forms are (i) an anatomo-politics of the human body, and (ii) a bio-politics of population. The first form Foucault identifies with the disciplinary practices perfected in armies, schools and factories. The second form he identifies with the regulatory controls of state administrations and their knowledge-producing bodies. ${ }^{5}$ According to Foucault, one of the characteristic features of biopower is the continuous nature of its application, in comparison to the discontinuous nature of sovereign power. But what is the nature and source of the continuity or continuities that are relevant to biopower? The suggestion offered in this paper is that the continuities posited or created in statistical measurement are a 
source and support of the social continuities imposed in social standardization. To understand Foucault's account of normalization as a crucial component of biopower, then, it will be useful to consider some of the basic conceptual components of the statistical notion of the normal curve, such as the mean or average, and the ratio.

In statistics, the normal distribution, or normal curve, has been interpreted in varying ways over the course of its history. It is sometimes called the Gaussian error law because of its origin as a technique for the correction of measurement in the physical sciences. It is also called the "Bell Curve" because of its characteristic shape. Its minimal description must include the two notions of mean and dispersion. In its social scientific employment, it is a graphic representation of the distribution of frequencies of values for a given measured property, with the most frequent values being those in the distribution that cluster around a mean or average in a single peak. ${ }^{6}$

One common objection to the use of the statistical notion of the norm is that since its use often vacillates between a descriptive and a normative sense it is fallaciously equivocal. This is so, and we will see that Foucault has a fruitful insight about this duality. But the paper aims to show that there are grounds for supplementary concerns about the nature of statistical social measure. These concerns are of two sorts. The first is that significant instances of covert equivocation and tacit amalgams occur on the very level of the statistical concepts of mean and ratio. That is, the paper suggests that statistical social measurement is ontologically problematic on the very level of the conceptual composites expressed in statistical measures and distributions and not only on an allegedly duplicitous subsequent prescriptive application of an allegedly-descriptive conceptual instrument.

The second is that the character of lived experience in the age of biopower is conditioned by the statistical panopticism that the new statistical tools permit. Attention to the refined level of the "microphysics" of biopower reveals a mathematics of measurement that yields the possibility for bodies to be lived as fundamentally comparative on the level of the life of the body and the life of the population and species. Relative to previous periods dominated by the binarizing function of legal prohibition, a new kind of comparability emerges, according to Foucault. That is, the kind of comparability available to and characteristic of bodies and groups changes with the advent of the modern statistical notion of a normal distribution.

The proposal advanced is that it is the continuous nature of 


\section{MARY BETH MADER}

some statistical distributions, and the statistical use of basic mathematical notions such as the ratio and the average, that ground the continuity of both individuals and collectivities in Foucault's account of modern biopower. That is, the mathematical notion of continuous magnitude replaces the notion of analogy as the operative concept that homogenizes relations of individuals to larger social unities. With the spread of the statistics of population and their role in the constitution of subjects, then, social relations literally become rationalized, or more precisely, ratio-ized. More precisely, one can trace a genealogy of the transitions, first, from a statistics of qualitative description, then, to a statistics of elementary two-dimensional quantitative comparison and, finally, to the ampler multidimensional quantitative comparative technology of statistical distributions. This means that the life of bodies and populations is ratio-ized in finer and finer ways, with increasing possibilities for inter-comparison.

To begin to establish these points, attention must be paid to evidence of Foucault's thought on the norm in the statistical sense. Accordingly, what follows are indications of the import of this statistical theme in select texts: Abnormal: Lectures at the Collège de France, 19741975, ${ }^{7}$ Discipline and Punish: The Birth of the Prison, ${ }^{8}$ The History of Sexuality, Volume I, and Sécurité, Territoire, Population: Cours an Collège de France. 19771978. ${ }^{9}$ Mentions of techniques of quantification as instances of "social control" found in "disciplinary societies" are not infrequent in these texts. Only some of the most salient instances are included here. ${ }^{10}$

\section{Abnormal: Lectures at the Collège de France, 1974-1975}

In the context of an analysis of the relations between nineteenth-century legal and medical institutions, Foucault argues that certain notions, notably those of perversity and danger, help to join the two types of institutions. The notion of perversion allows the meshing of legal and medical concepts and the notion of danger permits exchanges and collaborations between legal and medical institutions. Foucault describes the articulation of these concepts and institutions onto each other as the production of a kind of continuity: these linking notions install a "protective continuum" that combines criminal offense with medical abnormality. Linking notions of this kind are described as "switch points" or échangeurs that allow legal and medical notions to enter and operate in each other's domains. Interestingly, Foucault identifies the operative strength of these switch points with their epistemological fragility. About this sort of operative conceptual and 
institutional switch point, he writes: "the weaker it is epistemologically, the better it functions." "11 For the medico-legal opinion that arises on the basis of this notional articulation is inconsistent with the "terms .. . norms ... and formation rules" of both the fields of law and medicine. ${ }^{12}$

One of the key conceptual marks of this new category of medico-legal expertise is precisely that of continuity. Here, we find Foucault's repeated identification of one of the novel features of modern biopower, in this case its disciplinary version: a gradational ontology replaces one of opposition. "Expert medico-legal opinion is not deployed in a field of opposition, but in a field of gradation from the normal to the abnormal." 13

Foucault contrasts two forms of social control in the West, one that works by exclusion and another that works by inclusion. The first casts out individuals, creating two masses of people that are strangers to each other, as is the case with the exclusion of lepers in the Middle Ages. This characteristically medieval form of social control is aimed at purification of the community and its practice extends into the start of the eighteenth century. At that point, the second form of social control replaces the exclusionary form. This form is actually an eighteenth century re-emergence, Foucault claims, of another medieval form of social control. This second form is based on the social technologies of monitoring and registering that was devised for the management of plagues. It requires constant surveillance and registering of the conditions of individuals in a population struck by plague. The power correlative to this newly re-operative form of social control is "continuous in two senses." 14 There is (i) an organizational, structural continuity and there is (ii) a temporal continuity of surveillance. That is, the town is sectioned into spatial units of varying levels of size, within a general topographical grid, and inspectors and agents of political power per se are assigned to these sections. But, further, time is likewise sectioned and assigned such that inspectors can create registers that record the residents' conditions at established regular intervals.

This inclusive form of social control works by individualization: "there is a series of fine and constantly observed differences between individuals who are ill and those who are not. It is a question of individualization; the division and subdivision of power extending to the fine grain of individuality." ${ }^{\prime 15}$ This is a point at which to see Foucault's frequent claim that biopower is productive, and to grasp the relation between this productivity and the multiplication of epistemologically refined specification techniques for the control and 


\section{MARY BETH MADER}

comparability of individuals. The Classical Age invents "a power that does not act by separating into large confused masses, but by distributing according to differential individualities." ${ }^{\prime \prime}$ Hence, Foucault holds that "the norm brings with it a principle of both qualification and correction." That is, a central part of the uniqueness of normalization, as opposed to prior exclusive forms of power, is that it controls precisely by qualifying, but by qualifying bodies with quantifiable qualities. By endowing bodies with measurable features, it installs the conceptual basis for their control and management.

In the exclusive form of social control, the excluded group is juridically and politically "disqualified." ${ }^{17}$ But one might add that it is also, importantly, not qualified in the sense that its members are not classified according to a rigorous, refined and internally-gradated taxonomy; they are not endowed with quantifiable qualities. The story of an individual's inclusion, then, will in part be the tale of their qualification in this latter sense. That is, their quantifiable comparability, and hence both their individualization and their differentiation, will permit their control by the method of inclusion. Those controlled by inclusion will be qualified by means of conceptual techniques that quantify. The kind of refined qualification that will allow both their knowability and their correction or control crucially relies upon quantification. Most importantly in the view proposed here, it will depend upon the continuities - institutional, technical, conceptual, pragmatic - that are implied by the mathematical continuity inherent in the quantifying methods deployed by states in the emerging practice of "statistics." 18

\section{Discipline and Punish: The Birth of the Prison}

This book includes particularly useful evidence of Foucault's view that it is the production of continuities that makes normalization a novel form of social power. Toward the end of the book, Foucault describes the heterogeneous generalization - from "delinquent" youth to "the entire social body" _ of a carceral form of disciplinary normalization first found in quasi-penal institutions. In this account of the generalization of the carceral form, Foucault emphasizes the constitution of multiple forms of continuities, across previous social divisions and discontinuities. One of the crucial actual conditions for this generalization is the fact that incarceration "functioned ... according to a principle of relative continuity." ${ }^{20}$ What he describes here is the making of a society in which deviation and infraction become 
interconvertible, a society that placed a binary system of offense against the law into communication with a distributive system of departure from a norm. This society crafted continuities on the level of institutions, punitive mechanisms, administrative procedures; it created a smooth series of penalties that extended from mere deviations from a norm to infractions of a law. ${ }^{21}$ For Foucault, it is this grand confection of a gradational social space that is the distinctive character of modern biopower. Far from a view in which modernity is characterized by its increased social fragmentation relative to premodern life, Foucault proposes an alternative picture in which modernity sees the achievement of a vast project of social linkage and homogenization. As Foucault writes, about the carceral network: "This vast mechanism established a slow, continuous, imperceptible gradation that made it possible to pass naturally from disorder to offense and in the opposite direction from a transgression of the law to a slight departure [écart] from a rule, an average, a demand, a norm." 22

So, the crucial component of this homogenization is the social technology of the norm. For it is the notion of a norm and its deviations, rather than a law and its infraction, that permits the calibration, correction, gauging, and management that is central to biopower. The notion of the norm is what permits power to assume a therapeutic guise. For if the lawbreaker and the law-follower can be situated on a continuum of lawful conduct, the corrigibility of the lawbreaker, and the fragility of the law-follower, come into sight. After all, what separates them but a mere threshold degree of one same substance, lawfulness of conduct? In this way, the discrete difference between lawbreaker and law-follower is overcome in the linear continuity of the new gradational technology of the norm.

The norm, then, functions within the carceral system, as the standard to which discipline must mold bodies, as in the punitivecorrective prison. But the continuity that characterizes the norm also operates to create a gradation between explicitly carceral and supposedly non-carceral practices of discipline. It is this gradation that makes prison acceptable.

In the subtle gradation of the apparatuses of discipline and of the successive 'embeddings' that they involve, the prison does not at all represent the unleashing of a different kind of power, but simply an additional degree in the intensity of a mechanism that has continued to operate since the earliest forms of legal punishment. ${ }^{23}$ 


\section{MARY BETH MADER}

It is as if the gradational power of the norm itself escapes its limited confines and begins to function as a ubiquitous social adhesive, creating passageways of numerical continuity between previously isolated cells of society, adjoining in administrators' statistical tables individuals with no lived contact. But it is not merely a matter of the fantastical approximations of figures in bureaucratic registers. For the purchase of biopower on the mass phenomena that are some of its objects occurs in its grasp and crafting of social and bodily approximations.

Foucault's treatment of the question of the descriptive or prescriptive status of the norm is especially important for understanding his claims about the modern conjunction of power and knowledge. Many commentators on the notion of norm note that it has both a descriptive and a prescriptive sense. Some, like Guillaume LeBlanc, find this worrying and duplicitous; others, like Stephen Stigler, seem to consider it innocent and trifling. ${ }^{24}$ The brilliance of Foucault's account of the norm, partially adopted in LeBlanc's thought, is that he refuses the common separation of the norm into these two senses or sorts, descriptive and prescriptive. He writes: "With this new economy of power, the carceral system, which is its basic instrument, permitted the emergence of a new form of 'law': a mixture of legality and nature, prescription and constitution, the norm." ${ }^{25}$

Foucault's insight is that it is intrinsic to this new notion of 'law,' that is, to the norm, that it combine prescription and description. It is not that to avoid error or confusion we must separate the two senses and simply attend with care to which sense operates at any given point. In fact, analyzing the norm into two separate kinds of norm misses the effective nature of this new hybrid invention for social control; it is precisely through this joining that this notion operates most powerfully. To insist on sharply distinguishing the two kinds of norm and to hold that failures of the application of the notion of the norm can be prevented by attention to their distinction is to radically mistake the collaboration of the two senses that is most proper and necessary to the norm, and which accounts for its pervasive and palatable force.

\section{The History of Sexuality, Volume I}

In the context of his discussion of the roots of modern biopower, Foucault claims that quantitative approaches to sexuality 
appear at the start of the $18^{\text {th }}$ century. He writes that in this period:

there emerged a political, economic, and technical incitement to talk about sex. And not so much in the form of a general theory of sexuality as in the form of analysis, stocktaking [comptabilite] ], classification, and specification, of quantitative or causal studies. ${ }^{26}$

For Foucault, this is part of the birth of a rational discourse on sex, an element of the explosion of "talk" on the topic of sexuality that speaks of it as something that must be managed, made useful, regulated for the general welfare, and optimized. He writes that it becomes a matter of "not the repression of disorder, but an ordered maximization of collective and individual forces." ${ }^{27}$ One of Foucault's chief examples of this is the eighteenth-century emergence of "population as an economic and political problem." ${ }^{28}$ Here Foucault explicitly mentions statistical objects: "birth and death rates, life expectancy, fertility, state of health, frequency of illnesses, patterns of diet and habitation." "These variables" are at the intersection of "the characteristic movements of life" and the "particular effects of institutions." 29

Most important to the argument of this paper is a passage that treats the distinction between law and norm. Foucault writes:

The law always refers to the sword. But a power whose task is to take charge of life needs continuous regulatory and corrective mechanisms. It is no longer a matter of bringing death into play in the field of sovereignty, but of distributing the living [being] in the domain of value and utility. Such a power has to qualify, measure, appraise, and hierarchize, rather than display itself in its murderous splendor; it does not have to draw the line that separates the enemies of the sovereign from his obedient subjects; it effects distributions around the norm. ${ }^{30}$

Here, it could not be clearer that the notion of norm at issue is, or is based upon, the statistical sense of a norm as the mean of a normal curve. This quote would tend to disconfirm interpretations of the notion of norm in Foucault that would identify it strictly either with a generalized notion of pre- or extra-legal prescription (Kelsen) or with a purely biological notion of normativity as the power of an organism to create new norms for itself (Canguilhem). Law breaks a citizenry into obedient and disobedient subjects. ${ }^{31}$ But the norm has a refined, multiplied classification scheme that operates on a scalar model. It is no longer a matter of a binary division; degrees of the measured feature 


\section{MARY BETH MADER}

function to locate individuals along a fundamentally uninterrupted line, which yet can accommodate numerous categorial divisions. Their inclusion in a statistical distribution permits pure inter-comparison of each to each and each to all.

This emphasis on the statistical sense of a norm likewise reveals how Foucault's understanding of a norm would distinguish it from a custom or a tradition. For neither of these seems to imply this pure comparability of persons or features obtained with their inclusion in a statistical distribution. (Nor, some would add, do they carry with them an implicit potential guide for correction or the potential for prescriptive use.) The norm in this sense is immanently self-referential; no genealogy, history, ancestry or external standard matters for determining it. The norm purports to register whatever is the case at any given sampling point. It does not appeal to an external standard in this descriptive sense. We will see, though, that the matter is more complicated than this and that there are other construals and uses of the normal curve.

\section{Sécurité, Territoire, Population: Cours au Collège de France. 1977- 1978}

Foucault's awareness of and interest in the role of statistical practices and knowledge is also confirmed in Sécurité, Territoire, Population: Cours an College de France. 1977-1978. In the lecture of February 1, 1978, Foucault proposes that the seventeenth century art of government was not simply a matter of theoretical elaboration in works of political thought. He writes about this art, rather, that:

One can observe its correlations in the [order of the] real $\ldots$.. it was also tied to an entire set of analyses and [kinds of knowledge that were developed since the end of the sixteenth century and which attained their full scope in the seventeenth century, essentially that knowledge of the State in its diverse facts, in its differing dimensions, in the different factors of its power, and this is exactly what one called 'statistics,' as the science of the State. ${ }^{32}$

Foucault also clearly distinguishes his thought from the kind of legal thought, specifically that of Kelsen's positivist legal theory of norms, which proposes that systems of law necessarily repose on a fundamental system of norms. He specifies that his own thought concerns, rather, how "techniques of normalization" develop "from, beneath, in the margins of and perhaps even contrary to a system of law." 33

In this text, there are in fact two modes of normalization 
identified, corresponding to the "two basic forms" of biopower: (i) the disciplines and (ii) regulatory controls. ${ }^{34}$ Here, Foucault reserves the term normation for the norm found in disciplinary techniques used for the training of students, workers and soldiers. In such cases, a norm or standard is effected, is put into operation, in the very practices of training the bodies of these people. He writes:

Disciplinary normalization consists in first setting a model,
an optimal model that is devised in light of a certain result,
and the operation of disciplinary normalization consists
in try to make people, gestures, acts match this model,
the normal being precisely what is capable of conforming
to the norm, and the abnormal what is not capable of
this.

In the case of the disciplines, then, that is, with normation, the norm or model comes first, and the division into normal and abnormal follows. We also find here one of the clearest and most extended discussions to be found in Foucault's published writings of that other form of normalisation, namely, the kind that characterizes regulatory controls. This discussion takes place essentially in terms of statistics, and more specifically in terms of the normal curve. Foucault's central example of normalization is expressed in his account of the development of what might be called a proto-statistical epidemiology. ${ }^{36}$ He describes the nineteenth-century development of the increasingly refined applications of the techniques of the normal curve to medical data on disease incidence.

First, there is the creation of the continuity of a population by means of statistics. ${ }^{37}$ That is, sick and well are joined in a single population unit; they are not ontologically segregated. From this, a normal curve of morbidity or mortality is produced.

The population is a set of elements inside of which one can note constants and regularities even down to the level of] accidents, and inside of which one can locate the universal of desire that regularly produces the benefit of all, and relative to which one can discover a certain number of variables upon which this benefit depends, and that are capable of modifying it. ${ }^{38}$

It is the constitution of the population as a natural entity that Foucault identifies as a pivotal move in the conceptual transition from human kind (genre humain) to species, and hence in the biologization of human beings, of their insertion into a common epistemological field with all 


\section{MARY BETH MADER}

living species. The notion of population lodged human beings firmly in among "other living beings." 39

Second, Foucault describes the "interplay of differential normalities" that operates in the kind of normalization that characterizes regulatory control. For example, the statistical analyses will generate normal distributions for syphilis by cases infected and for deaths from syphilis, as well as for syphilis deaths for each age, region, town, quarter, and profession. The technique then will be to attempt to reduce all of the most deviant of these normal curves to the level of the general normal distribution of mortality. This is the "interplay of differential normalities." So, here Foucault specifies that this "normalization" "in the strict sense" occurs in a manner nearly the reverse of that of the disciplinary sort of normalization, or normation. ${ }^{40}$ What is reversed? In the case of this normalization in the strict sense, or normalisation, the identification of normal and abnormal precedes the identification of the norm. The various normal curves are collected and compared. Then, "certain distributions" are "considered more normal than others, or in any case more advantageous than the others. It is these distributions that will serve as norms. The norm is an interplay [un jeu] within differential normalities." ${ }^{\prime 11}$ Hence, for Foucault, a norm in the strict sense is set by means of this comparative study of normalities found in normal distributions.

\section{Measurement and social mereology}

The Belgian astronomer Adolphe Quetelet is credited with first applying the Gaussian error curve, or "Bell Curve," to social objects in his 1835 book, Sur l'homme et le développement de ses facultés, on Essai de physique sociale. ${ }^{42}$ Astronomers had devised the method of taking multiple measures of planetary positions and, finding that those numbers formed the characteristic bell-shaped distribution, using the mean of that distribution for prediction of planetary position. Despite the imprecision of astronomical measurement, then, the "Bell Curve" or "normal distribution," was used to determine reliable results. When multiple measurements were taken they were discovered to cluster around a central value; this mean of the distribution was used as a way of canceling out measures that were presumed to be erroneous, but not able to be specifically identified as such. The values farther away from the mean value were the lesser reliable measurements. The mean of the normal distribution, then, stands in for the accurate measurement that is sought but is technologically unachievable. 
It was Quetelet who extended this practice of corrective measurement from astronomical to social objects. This extension of the mathematical law of error to social objects ushers in the $19^{\text {th }}$ century era of "social arithmetics," "social mathematics" and "social physics" and thus marks the advent of what becomes quantitative sociology. It is the frequent occurrence of the normal distribution in the growing nineteenth century collection of social data that prompts Quetelet to make this extension of the Gaussian error law from astronomical to social objects. He supposed that the mean of the normal distribution in the case of the social object should have the same kind of errorcanceling accuracy as the mean in the case of the astronomical object.

Quetelet is also the source of the notion of the average man, the statistical composite of a panoply of measurements of features of groups of men; the sum of the means of the height, weight, intelligence and other moral features of a group would paint a mathematical portrait of the average man. Theodore M. Porter discusses the intellectual career of Adolphe Quetelet's notion of l'homme moyen and its adoption and extension by Henry Thomas Buckle in the latter's History of Civilization in England. ${ }^{43}$ Along one of its tributaries, the descent of the notion proceeds from Adolphe Quetelet to Buckle to John Stuart Mill. ${ }^{44}$ According to Porter, Quetelet, Buckle and Mill were impressed by the relative reliability of statistical knowledge about collections or groups compared to the much more precarious knowledge of individuals. Porter explains the great appeal to nineteenth century thinkers of the advances in mathematical statistics and their application to social problems:

Quetelet and Buckle were read, moreover, by a generation of Europeans who were imbued with a sense of society as a fundamental and preeminently historical entity that was capable of having its own laws. Statistics acquainted these readers with a new form in which natural laws could reveal themselves, one whose distinctive features were noted by writer after writer. The individuals are so numerous, and subject to so complex an array of circumstances, that it is impossible to foresee with any reliability their future behavior. Yet whenever a large number of individuals is considered at once, "the influence of contingencies seems to disappear before that of general laws." 45

We can summarize the thought that exerted such attraction with Porter's line that itself quotes from Mill's $A$ System of Logic. "statesmen may rely on probable statements regarding multitudes, for 'what is true 


\section{MARY BETH MADER}

approximately of all individuals is true absolutely of all masses'." ${ }^{\prime 6}$ This thought invites a number of speculations on the ontological presuppositions of statistical laws in their application to social questions.

To speculate, then: It seems there is an obscured, curious and powerful assumption operating in this thought. This assumption is that the trait that either is an individual or is attributed to an individual is the same sort of trait, or is sufficiently the same, as the trait attributed to the group or collection of individuals.

Insufficient attention is generally paid to a change of sense that occurs in some uses of the notion of an average with respect to a property that is the object of measure and comparison. In contemporary popularizations of social statistical results, we can often identify a multiphase movement from:

(i) Individual measurement. data collection of individual measurements of a selected property of individuals to (ii) Aggregation of individual measurements: these individual measurements are tabulated together to

(iii) (a) Mean of the measurements: the average derived from the aggregation of individual measurements and said to be a property of the group of individuals to

(iii) (b) Rational redistribution of the results of aggregation and averaging: a frequentist interpretation of that group property that lends it back to individual members of the group, in the form of calculated likelihoods, or risks, expressed as ratios or rates, or

(iv) Generalization of the results: extension of results from the group understood as a representative sample of a larger population to that larger population or to its member individuals.

The first three of these moves concern us for the moment. It seems that in such a triphase movement, a shift in kind of measurement takes place in the move from individual (i) to aggregated (iii) measurement. Further, this transition can be described as one in which the sense of the property at issue itself must be considered changed for the reason that it applies to a significantly different kind of being in the group (iii) than in the individual (i). That is, the property applied to the individual is not the same as the property applied, by averaging and ratio-construction, to the group. ${ }^{47}$

\section{The case of suicide}

To see this, we might consider the case of suicide. Porter notes 
that the objects of statistical regularities that so captivated nineteenth century thinkers were "murder, suicide, the misaddressing of letters." 48 This was because of the great constancy in the rates of these phenomena for specified societies. Though individual persons in a society appear to act in voluntary but unconcerted and irregular ways, the collective facts about the behavior of those same individuals taken as a total group are regular and constant. For nineteenth century thinkers, the stability of the mean implied a supporting substructure of social law; statistical regularities implied the existence of general laws governing society. "Crimes occur in the same numbers year after year, obeying ostensible social laws..."49

With respect to suicide, then, we can distinguish three important cases. We omit consideration of the average or (iii A), for the moment, although the same point can be made about the average as about the ratio, when we realize that an average can also be expressed as a ratio, namely, the ratio of the sum of a set of values to the cardinal number of those values. Accordingly: (i) an individual can be a suicide, and (ii) a society composed of individuals, some of whom are suicides, can have a total figure for the quantity of individual suicides; and (iii B) the society can have a ratio of suicides to non-suicides or a suicide rate. Often, this societal probability or proneness to suicide is re-distributed to individual members of society; that is, it is thought to convey information of some import for not just the social body as a whole but for its individual members. And (iv): This ratio or rate can then be interpreted in a probabilistic sense such that a society can be said to be more or less likely to contain individual suicides (the notion of risk).

So, with respect to the society, the two relevant figures are: (ii), a figure for the quantity or absolute number of individual suicides for a given society, on the one hand, and (iii B), a figure for the suicide rate of a given society, on the other hand. The first is a figure each unit of which refers to and characterizes individual members of a society. The second figure is essentially a ratio of suicides to non-suicides for the total population capable of suicide. The first figure expresses the cardinal or integral property of a group, namely, the group of all individuals who are suicides. The second figure expresses a rational property of a greater and different group, namely, the aggregate of suicides and nonsuicides. ${ }^{50}$

The relevant-and questionable-assumption here is that the term 'suicide' retains the same sense in its role in these two figures. The second use of the term 'suicide' applies to the group of only suicides. 


\section{MARY BETH MADER}

The third use of the term applies to the compound group of suicides and non-suicides, expressing, in fact, an asserted relation between them in the language of ratios. But we can wonder whether the differences between the scope ((i) single individual, (ii) group of suicides, (iii) total possible suicides) of the term's reference might make a difference for its sense. And if it does, we can inquire into the precise relation of those senses to each other, and of those objects to each other. The term 'suicide' when applied to an individual [(i)] or to a group of individuals [(ii)] refers to actual persons who have committed suicide. ${ }^{51}$ (And it is a term or a figure that refers to the past.) The term "suicide" in the expression "suicide rate" no longer refers to any person or persons, but to a relation between numbers or quantities alone. There is no more a "suicide" rate, average or norm than there is an average "height" of a group of persons each of which has a height. Of course, there are rates, averages or norms of numbers or quantities in relation to each other, but these are not rates "of suicide" or averages "of heights," they are rates and averages of numbers and quantities.

The objection advanced here is that the term applied to a society in the figure of a suicide rate or ratio [(iii B)], no longer refers to the same genera of object as does its source term ("suicide"), that is, to an individual or even to a group of individuals. Rather, it refers to a quantitative relation between two measures associated with groups. The move from individual to rate, by way of the group, amounts to a radical shift of ontological register. This ontological slide-from a single 'case' of suicide to a total figure for the group of all 'cases' of suicide to the numerical expression of the relation between two groups, the group of actual suicides and the group of possible suicides, one of which contains the other-is significant.

One might locate its chief significance in the move from individual to the figure for total suicides, that is, from (i) to (ii). In that case, one might stress a leap from non-quantitative to quantitative description, or perhaps from singular to plural enumeration or description. Let us rather indicate the significance of the slide that occurs between (ii) and (iii B), that is, a slide from integral to rational numerical expression. For, the figure for (ii), the total number of suicides, is an integer not expressed as a rational number. But the figure for (iii B), the suicide rate, is a rational number. The first of these two figures assigns an absolute quantity to a group of individual members joined and homogenized by the bureaucratic, medical, police and social scientific application of a definition of suicide. The second of the two 
figures assigns a proportional quantity between two figures of the first sort, namely, the group of suicides and the group of all social members capable of suicide. The paper's claim here is that these two types of figures treat two different ontological orders. The first is of the order of groups, the second is of the order of relations between groups. ${ }^{52}$

\section{Average, mean and norm}

Typically, contemporary statistical uses of such rates deploy a probabilistic interpretation of the relative frequencies expressed in such rates, and then re-apply or distribute these frequencies to all individuals in the total group studied, as well as to each individual in the total group. In the average, the standardized feature of the subgroup (here, suicides) is distributed over the total group (the whole society, or actual suicides plus potential suicides) to give a suicide likelihood or risk for any random member of the total group. This mathematical sharingout or allotment of the likelihood or risk has historically implied a correlative political sharing of a hazard constructed as a quantity that is evenly distributable over the entirety of the total group. The average equalizes by distributing evenly.

In the average distributed back over the society and shared out to its members, we find the occlusion of the relation between the groups [(ii)] that go to compose the figure of the rate. In this case, suicide rates express the relation between several groups. Depending on the kind of rate, these groups will be the set of actual suicides, the set of possible suicides, and the set that is the union of these. But the average distributed back over the society and shared out to its members is the likelihood of suicide for the individual member of society. It is this distribution of the ratio back to the individual elements of the grouping in the form of likelihoods that occludes the rational nature of the rate. In other words, it conceals the fact that here it is a matter of the relation between the relevant groups.

Moreover, in sharing out the relation between the relevant groups to each member and to all members of the society, the spectral nature of the set of suicides is given new and continuing life. The set of suicides is spectral because it denotes a collection of the dead; its members are no longer, at least when compared to the potential suicides that comprise the denominator in the ratio of actual suicides to potential suicides. But the suicide rate distributed over the remaining individuals legates to each a vital parcel of the set of actual suicides; they leave behind the risk of resembling them. 


\section{MARY BETH MADER}

If we think that the sense of the term 'suicide' remains significantly unchanged in the cases noted, we are deceived by the cooperative power of the grammar of adjunction and the arithmetic of averages. The specifically ontological shift indicated here is significant because the adjectival and arithmetic assimilation effected in these kinds of cases does the conceptual labor of homogenization that is subsequently found in discourses of social and political comparability in the form of claims purported to be merely and innocently descriptive and representative ones.

So, aside from the oft-noted problem of actually crafting the definitions under which observed phenomena will be classed (the problem of determining what counts as measurable qualities), and the problem of the norm's equivocal descriptive or prescriptive status, there is also the problem of the sort of overlooked equivocations on the ontological or conceptual 'level' identified here. Crucially, the shift from the integral numerical expression found in (ii) to the rational numerical expression of (iii) is a shift from one ontological register to another.

If this claim about a shift in ontological register is accepted, the oft-obscured workings of the novel kind of comparability that emerges with the widespread use of social statistics can be seen with greater clarity. It is the mathematical continuity of the number line, or an assumption of continuous quantity, that is the crucial medium for the creation of the social continuities that guarantee the modern form of social comparability that Foucault identifies as characteristic of biopower. For it creates the "equality-with" compassed in the etymology of the verb "to compare" such that ontological differences and discontinuities between individuals, groups, and relations between groups are homogenized without notice. It is the continuity of number itself that renders both the individuals counted and the ratio of group to group comparable objects to which basic and sophisticated mathematical operations can be applied. Statistical ratios express social relations in a concealed manner and create abstract relations through the comparability generated by numerical continuity; social discontinuities are homogenized in the continuity of quantum.

Many more qualifications could be added to this account. Space permitting, we could in a more refined account explore the fact that strictly speaking the continuity of number in statistics predates the invention of the statistical norm. Desrosières' work on the emergence of German Statistik and English "political arithmetic" is particularly illuminating about this history. For he discusses the many changes in 
statistical representation and aim beginning with the use of descriptive statistical tables, in which, for example, states compiled data in columns and rows. In German descriptive statistics, a column of states was listed, as well as descriptive entries for various categories of state interest, also arranged in columns. One could then read across a line for a summary of a single state's profile, or down a column to compare all the listed states in a particular category. The entries in this kind of descriptive statistical table were not figures but words. Desrosières traces the transitions from this sort of statistics to a quantitative twodimensional "crossed table" system. He holds that it was through reading down a column of this sort of table that the notion of a "variable" appeared. So, plainly, a kind of comparability exists in such tables. In the second stage, though, verbal descriptions are replaced by numbers, and we have the emergence of a specifically quantitative, twodimensional "space of comparability." 53

Part of the novelty of the statistical norm, then, is that by contrast to this two-dimensional table it is a multidimensional space of comparison, and as such it crafts a "multidimensional continuum." 54 The normal distribution is a highly elaborate tool for the presentation and coordination of multiple quantitative relations. It is the conceptual complexity of the normal distribution that has prompted restriction of the discussion so far to its simpler composite notions of ratio and average. In the novel technology of the normal curve, subgroups of a total group are determined to be subgroups by reference to the mean of the total group. Of course, the distribution itself may be made on the basis of a single factor or feature, that is, it may be one-dimensional in this factorial sense. But the distribution permits comparisons of subgroups to each other and to the mean, as well as comparisons of individuals or individual values anywhere on the curve with any other individuals in the total group. The individual is characterized multidimensionally: it is situated relative to the relation of any other individual to the mean, and not simply or directly relative to any other individual. And the mean is allegedly a feature of the total group. So, the individual is characterized relative to a feature attributed to the group of which it is a part, namely, the mean value of the total group. The individual is characterized relative to a general feature of the total group, while this general feature is partially derived from the value of any given individual value, since it is the mean of all the individual values aggregated. The most common value, then, becomes the point of reference for the location of every value that is represented. The complexity of the 


\section{MARY BETH MADER}

multidimensional space of comparability found in the instrument of the statistical distribution known as the normal curve thus permits multiple kinds of comparisons through the intermediary of the mean of the curve.

One argument of this section has been that the statistical mean does not characterize the group, it characterizes the arithmetic relations of the measures of the group. This is a controversial claim and one that is at the heart of continuing debates about the validity of social statistics. This controversy attended the emergence of these techniques with Quetelet's invention of the average man. Quetelet, as Hacking puts it:

transformed the theory of measuring unknown physical quantities, with a definite probable error, into the theory of measuring ideal or abstract properties of a population. Because these could be subjected to the same formal techniques, they became real quantities. ${ }^{55}$

Hence, it is the properties endogenous to mathematical objectscontinuous quantity, the basic laws and operations of arithmetic - that create the alleged comparability and continuities of populations and other social phenomena constituted as the objects of social statistics. The conceptual sleight that performs this conversion seems today still to pass undetected.

\section{Endpoints}

With respect to the approach of this paper to Foucault's thought, one might wonder about the relation between the conceptual and non-discursive dimensions of his work. About this matter, it should be noted that the present focus on the conceptual source of the social continuities of the era of biopower is not made at the expense of the import of Foucault's careful historical analyses of the role of nondiscursive elements in the creation of social continuities. For, on his view, these elements themselves come to be ordered, shaped and coordinated in large part on the basis of this novel technology that is the norm. The ubiquitous application of the normal curve as a means of social management is itself constitutive of those regulatory controls that Foucault claims take species, populations and races as their objects.

This paper has sought to draw from Foucault's work an implicit reason for which he can claim that modern biopower is a 
"continuous" form of power: it creates social continuities on the basis of politically-instituted mathematical continuities through the immense apparatuses of linked regulatory institutions and practices that employ statistical tools. When expressed as ratios, actual social relations between groups of people are masked in these figural expressions that employ the specific features of mathematical objects to characterize people and groups of people. We might say that the normal curve in social statistics is a pseudo-relation to others that is in its essence a detour through the numerical amalgamation of all-a ligature so ontologically alien to the social world that it fails to quality as a relation at all. The conceptually duplicitous statistical reason that comes to order life in modernity is, as Foucault never ceases to argue, a creation of the new conjunction of power and knowledge that installs a novel, specifically statistical form of social continuity and comparability. It is on the basis of this insight that we can conceive the specificity and the force of Foucault's account of modern biopower.

University of Memphis

\section{Notes}

Reprinted by permission from Sleights of Reason: Norm, Bisexuality, Development by Mary Beth Mader, the State University of New York Press copyright symbol 2009, State University of New York. All rights reserved.

${ }^{1}$ See especially: Alain Desrosières, La Politique des grands nombres: Histoire de la raison statistique (Paris: La Découverte, 2000); The Politics of Large Numbers: A History of Statistical Reasoning (Cambridge, MA: Harvard University Press, 1998); Ian Hacking, The Taming of Chance (Cambridge: Cambridge University Press, 1990); Theodore M. Porter, The Rise of Statistical Thinking, 1820-1900 (Princeton: Princeton University Press, 1986); Stephen M. Stigler, Statistics on the Table: The History of Statistical Concepts and Methods (Cambridge, MA: Harvard University Press, 1999).

${ }^{2}$ Michel Foucault, The History of Sexuality, Volume I: An Introduction (New York: Random House, 1990), 144. [HSE] Histoire de la sexualité I: La volonté de savoir (Paris: Gallimard, 1976), 190. [HSF]

${ }^{3}$ Georges Canguilhem, The Normal and the Pathological (New York: Zone Books, 1991). Le Normal et le pathologique (Paris: Presses Universitaires de France, 1966).

${ }^{4}$ Though Foucault expresses clear interest in Canguilhem's account in The Normal and the Pathological of norms in medicine, biology and social theory, his own uses of the notion depart from Canguilhem's thought on the topic. Yet Canguilhem's treatment of the statistical notion of the norm in the context of the medical distinction between normal and pathological remains an important conceptual background to Foucault's own account of 


\section{MARY BETH MADER}

normalization. That is, though Foucault focuses more on a strictly biological notion of norm in The Order of Things (New York: Vintage Books, 1973), and on the norm as social standardization, political concept and inclusive, corrective tool elsewhere, we would do well to understand his varying uses of the notion of a norm in relation to the statistical notion discussed by Canguilhem and others.

${ }^{5}$ Foucault, HSE, 139; HSF, 183.

${ }^{6}$ See Desrosières, La Politique des grands nombres, 97-8. For a technical definition of the mathematics of the normal curve, see Ian Hacking, Logic of Statistical Inference (Cambridge: Cambridge University Press, 1965), 71-3. For histories of the varying interpretations and uses of the normal curve in social statistics, see Desrosières, La Politique des grands nombres, Ian Hacking, The Taming of Chance and Porter, The Rise of Statistical Thinking, 1820-1900.

${ }^{7}$ Michel Foucault, Abnormal: Lectures at the Collège de France, 19741975. Trans. Graham Burchell (New York: St. Martin's Press, 2003). Les Anormaux: Cours au Collège de France (Paris: Editions du Seuil/Gallimard, 1999).

${ }^{8}$ Michel Foucault, Discipline and Punish: The Birth of the Prison, Trans. Alan Sheridan (New York: Random House, 1977). [DP] Surveiller et punir: Naissance de la prison (Paris: Editions Gallimard, 1975). [SP]

${ }^{9}$ Michel Foucault, Sécurité, Territoire, Population: Cours au Collège de France. 1977-1978 (Paris: Gallimard, 2004). [STP] All translations from this text are my own.

${ }^{10}$ For reasons of space, I omit Foucault's utterly relevant discussion of the changes in dominant kinds of comparison (in The Order of Things, Part I, Chapter 3: "Representing"), and his account of the transition from an emphasis on function to one on norm (in The Order of Things, Part II, Chapter 10: "The human sciences").

${ }^{11}$ Foucault, Abnormal. 33.

${ }^{12}$ Foucault, Abnormal, 41. "Essentially, both justice and psychiatry are adulterated in expert medico-legal opinion."

${ }^{13}$ Foucault, Abnormal, 42 (my emphasis).

${ }^{14}$ Foucault, Abnormal, 45.

${ }^{15}$ Foucault, Abnormal, 46.

${ }^{16}$ Foucault, Abnormal, 48.

${ }^{17}$ Foucault, Abnormal, 43.

${ }^{18}$ Historians of statistics tie the etymology of the word 'statistics' to state practices of collecting figures for the purpose of describing the features of the state and its population. See Hacking, The Taming of Chance, Chapter 3, "Public amateurs, secret bureaucrats" and Desrosières, La Politique des grands nombres, 1: "Le préfet et le géomètre."

${ }^{19}$ Foucault, DP, 296, 298. SP, 303, 305.

${ }^{20}$ Foucault, DP, 299; SP, 306.

${ }^{21}$ In $\mathrm{On}$ the Genealogy of Morals, Nietzsche deflates the compensatory justification of punishment, asking: "to what extent can suffering balance debts or guilt?" (Trans. Walter Kaufmann. New York: Random House, 1989, 65). For Nietzsche, the achievement of this "idea of an equivalence between injury and pain" (63) has required a long "labor performed by man upon himself" (59) so as to make him "to a certain degree necessary, uniform, like among like, regular, and consequently calculable." (59) It is plain that in Discipline 


\section{FOUCAULT AND SOCIAL MEASURE}

and Punish Foucault narrates the modern tale of the installation of this very equivalence over which Nietzsche puzzles. Foucault writes: "The 'carceral' with its many diffuse or compact forms, its institutions of supervision or constraint, of discreet surveillance and insistent coercion, assured the communication of punishments according to quality and quantity; it connected in series or disposed according to subtle divisions the minor and the serious penalties, the mild and the strict forms of treatment, bad marks and light sentences." (Foucault, DP, 299; SP, 306).

${ }^{22}$ Foucault, $D P, 298 ; S P, 306$.

${ }^{23}$ Foucault, $D P, 302 ;$; $P, 309$.

${ }^{24}$ Guillaume LeBlanc, L'Esprit des sciences bumaines (Paris: Vrin, 2005), 74. LeBlanc argues that shifts in the social sciences from a descriptive sense of the norm to a prescriptive one reveal its structuring amphibological play. "Every normative regime stems at once from the average and from prescription. That is, there is no average that does not tend to become a prescription and no prescription without ambition to become an average." (My translation.) See also Stephen M. Stigler, Statistics on the Table: The History of Statistical Concepts and Methods (Cambridge, MA: Harvard University Press, 1999), 430: "'normal' - the delicious ambiguity it brings to both scientific and public discussion with its embodiment of both the usual and the ideal..."

${ }^{25}$ Foucault, DP, 304; SP, 310.

${ }^{26}$ Foucault, HSE, 23-4; HSF, 33. Comptabilité may be rendered as 'accounting.' Also relevant are: 'But it [sex] gave rise as well to comprehensive measures, statistical assessments, and interventions aimed at the entire social body or at groups taken as a whole. Sex was a means of access both to the life of the body and the life of the species." (HSE, 146; HSF, 192); "power is situated and exercised at the level of life, the species, the race and mass phenomena of population.” (HSE, 137; HSF, 180)

${ }^{27}$ Foucault, HSE, 24-5; HSF, 35.

${ }^{28}$ Foucault, HSE, 25; HSF, 35.

${ }^{29}$ Foucault, HSE, 25; HSF, 36.

${ }^{30}$ Foucault, HSE, 144; HSF, 189-90. My emphases.

${ }^{31}$ Foucault further proposes that the law functions increasingly like a norm, and the judicial institution is integrated more and more into "a continuum" of institutions (medical, administrative, etc). See HSE, 144; HSF, 190. For more on this notion of institutional continuity, see Abnormal: Lectures at the Collège de France, 1974-1975, Chapter 2: 15 January 1975.

32 STP, 104; 117, n. 31. The editors also note that Foucault's notes refer to V. John's Geschicte der Statistik (Stuttgart: F. Encke, 1884).

${ }_{33}$ STP, 58.

${ }^{34}$ The formulation can also be found in HSE, 139; HSF, 182-3.

${ }^{35}$ STP, 59.

${ }^{36}$ STP, 65: He interjects: "—-this is not yet epidemiology, well, the medicine of epidemics-"

${ }^{37}$ STP, 64: "This will consist in taking into consideration the wholewithout discontinuity, without break — of the sick and the non-sick, that is, in sum, the population, and to see what in this population is the coefficient of probable morbidity, or of probable mortality, that is, what is normally expected 


\section{MARY BETH MADER}

in the matter of the reach of the illness, in the matter of death linked to the illness in this population."

${ }^{38}$ STP, 76.

${ }^{39}$ STP, 77.

${ }^{40}$ STP, 65.

${ }^{41}$ STP, 65 (my emphasis). A footnote includes Foucault's additional remark that: "the operation of normalization consists in playing off against each other, and in making play off against each other, these differential distributions of normality."

42 Adolphe Quetelet, Sur l'homme et le développement de ses facultés, ou Essai de physique sociale (Paris: Bachelier, 1835). A Treatise on Man and the Development of his Faculties (London, 1842).

${ }^{43}$ Porter, The Rise of Statistical Thinking, 1820-1900, 60.

${ }^{44}$ For a chart of the historical development of social statistics, see also Desrosières, La Politique des grands nombres, 343.

${ }^{45}$ Porter, The Rise of Statistical Thinking, 1820-1900, 65. The quote cites Herman Merivale, "Moral and Intellectual Statistics of France," Edinburgh Review, 69 (1839), 49-74, p. 51.

${ }_{46}$ Porter, The Rise of Statistical Thinking, 1820-1900, 66.

47 This apparently is a difficult notion for many to accept. After drafting my argument, and finding some resistance to it, I was pleased to come across a like-minded argument. For apparently some of geneticist Richard Lewontin's readers also had trouble grasping the point, which prompted his explanation: "The height of a person is a natural attribute of a real object. If I average the heights of ten people, that average is not an attribute of any real object. There is no person with such a height, nor does it characterize the height of the collection of individuals since a collection of people does not have a height. The average is not even a height. It is simply the sum of a lot of measurements divided by the number of measurements. It is a mental construction. To assert that it is a real attribute of a thing is an act of reification (indeed, double reification!)." [Richard Lewontin, It Ain't Necessarily So. (London: Granta, 2000), 30]. Though this paper would not endorse the same ontology that Lewontin uses to characterize the error, the points he makes here are exactly what are at issue in the below discussion of the "ontological slide." With respect to the difficulty of this point, perhaps what misleads is that the average of a set of numbers is itself a number. But the average of heights certainly cannot itself be a height. Specifying under what conditions an average could be of the same kind of thing as the values of which it is an average is a task whose complexity exceeds this project's range. (We might also note that, strictly speaking, and contrary to Lewontin's assertion, as a matter of contingent fact it is possible that there be a "person with such a height." But it is certainly not necessary that any individual value combined to derive an arithmetic mean has or is the same value as that arithmetic mean.)

${ }^{48}$ Porter, The Rise of Statistical Thinking, 1820-1900, 63. Foucault clearly alludes to this nineteenth-century fascination with social statistical stability in The History of Sexuality I, here with respect to suicide: "This determination to die, strange and yet so persistent and constant in its manifestations, and consequently so difficult to explain as being due to particular circumstances or individual accidents, was one of the first 


\section{FOUCAULT AND SOCIAL MEASURE}

astonishments of a society in which political power had assigned itself to the task of administering life." HSE, 139; HSF, 182.

${ }^{49}$ Porter, The Rise of Statistical Thinking, 1820-1900, 64.

${ }^{50}$ An integer can be expressed as a ratio in a trivial sense, by using it as a numerator and the number 1 as a denominator. Plainly, I exclude such cases. Also, neither the group of suicides nor that of non-suicides is a selfconstituted social group; these are rather statistical artifacts. Further, I am thinking of a rate, in ontological terms, as fundamentally a species of ratio. I take this to be an uncontroversial assumption that does not deny various more refined definitions of a rate, say, as a species of ratio requiring a temporal value. Conceptually, a rate is a kind of ratio, and that is its primary sense here.

${ }^{51}$ Although Occam and like nominalists would reject the idea that (ii) refers to individuals. See Desrosières, La Politique des grands nombres, 91.

${ }^{52}$ I do not here employ the technical vocabulary of the mathematics of set theory, in which relations themselves are given an analysis in terms of sets. In fact, such an analysis transported into the context of social measure is a source of the problems identified here.

${ }^{53}$ Desrosières, La Politique des grands nombres, 67.

${ }^{54}$ Desrosières, La Politique des grands nombres, 297.

${ }^{55}$ Hacking, The Taming of Chance, 108 (my emphasis). 